\title{
Contractile properties of cardiac papillary muscle in streptozotocin-diabetic rats and the effects of aldose reductase inhibition
}

\author{
N.E.Cameron, M.A.Cotter and S. Robertson \\ Department of Physiology, University of Aberdeen, Scotland, UK
}

\begin{abstract}
Summary. This study examined the preventative effect of an aldose reductase inhibitor, ponalrestat, on contractile properties of heart left ventricular papillary muscles in rats having streptozotocin induced diabetes for 13 weeks. Both contraction and relaxation were slowed by diabetes. The time to reach peak twitch tension was increased by $21 \%$, and the time to relax to half peak tension was increased by $29 \%(p<0.01$, respectively compared to normal control animals). With ponalrestat treatment, the increase in contraction time was only $11 \%$, and relaxation was only slowed by $4 \%(p<0.05$ and $p<0.01$, respectively compared to diabetic controls). Diabetes also reduced maximum rates of contraction $(13 \%)$ and relaxation $(19 \%)$ and prolonged the time taken to reach peak relaxation rate $(36 \%, p<0.01)$. Ponalrestat had no effect on maximum contraction rates but was particularly effective in normalising relaxation rates $(p<0.01)$. Deficiencies with
\end{abstract}

diabetes were noted over a range of stimulation frequencies $(0.1-4.0 \mathrm{~Hz})$, and ponalrestat treatment was beneficial except at the highest rates. Diabetes and ponalrestat effects were observed over a temperature range of $25-37^{\circ} \mathrm{C}$. Ventricular sorbitol levels showed a 17-fold increase with diabetes $(p<0.01)$ and this was reduced by $67 \%$ with ponalrestat $(p<0.01)$. There were no changes in ventricular myo-inositol. It is possible that ponalrestat treatment prevented a defect in sarcoplasmic reticulum calcium handling which could be responsible in part for the deficits in contraction ability and mainly for the deficits in relaxation ability in diabetic cardiomyopathy, although this remains to be tested directly.

Key words: Aldose reductase, diabetic cardiomyopathy, myocardial mechanics, polyol pathway, ponalrestat, streptozotocin diabetes.
Diabetic patients have increased susceptibility to heart disease which may develop in the absence of hypertension or large vessel atherosclerosis and is thought to be a true cardiomyopathy. Functional studies reveal that patients have a shortened left ventricular ejection time, a longer pre-ejection period, and prolonged isovolumetric relaxation. This could be caused by changes in the contractile properties of ventricular muscle. Dysfunction correlates with the occurence of other complications, particularly retinopathy, nephropathy and neuropathy [1].

Similar changes in whole heart function have been observed in dogs [2] and rats [3]. Experiments on rat and rabbit papillary muscles demonstrated a slowing of isotonic and isometric twitches and reduced inotropic responses [4,5], which could be ameliorated by insulin therapy [6]. Similar contractile defects, recently observed in slow skeletal muscle, were normalised by aldose reductase inhibitor (ARI) and insulin treatment $[7,8]$. Cardiac and slow skeletal muscle are similar metabolically, having a high oxidative and low anaerobic potential. Neither are dependent upon insulin for glucose uptake. Thus, diabetic cardiac muscle may have increased polyol pathway activity which could underly contractile dysfunction. In the present study we exam- ined whether aldose reductase inhibition could prevent contractile changes in papillary muscle, thus providing a preliminary indication of any potential for treatment of diabetic cardiomyopathy.

\section{Materials and methods}

Mature, 14-week-old, male Sprague-Dawley rats from the Aberdeen University colony were used. All animals had food and water available ad libitum. Two groups of rats were made diabetic with a single i.p. injection of streptozotocin $(45 \mathrm{mg} / \mathrm{kg}$ ), and were $\mathrm{kept}$ alive for a further 13 weeks until the final experiments. A third group was maintained as a normal control group. One of the diabetic groups acted as untreated diabetic controls. The second diabetic group was treated with ARI (ICI 128436, ponalrestat [9], Imperial chemical Industries, Macclesfield, UK, $25 \mathrm{mg} / \mathrm{kg}$ ) daily by gavage. Blood glucose levels were monitored weekly (tail prick samples), as was glycosuria (VisidexII and Diastix, Ames, Slough, UK). Final plasma glucose levels were measured using a glucose analyser (Beckman Instruments type 2, Fullerton, Calif, USA) on samples taken from the heart when rats were killed.

In the final experiments, animals were stunned and the heart was rapidly removed. A papillary muscle was dissected from the left ventricle, a silk suture was placed around its chordae tendonae, and the other end was secured by a plastic tissue clip. The muscle was mounted vertically in a tissue bath with the suture attached to a rigid glass hook and the tissue clip connected to an isometric transducer 


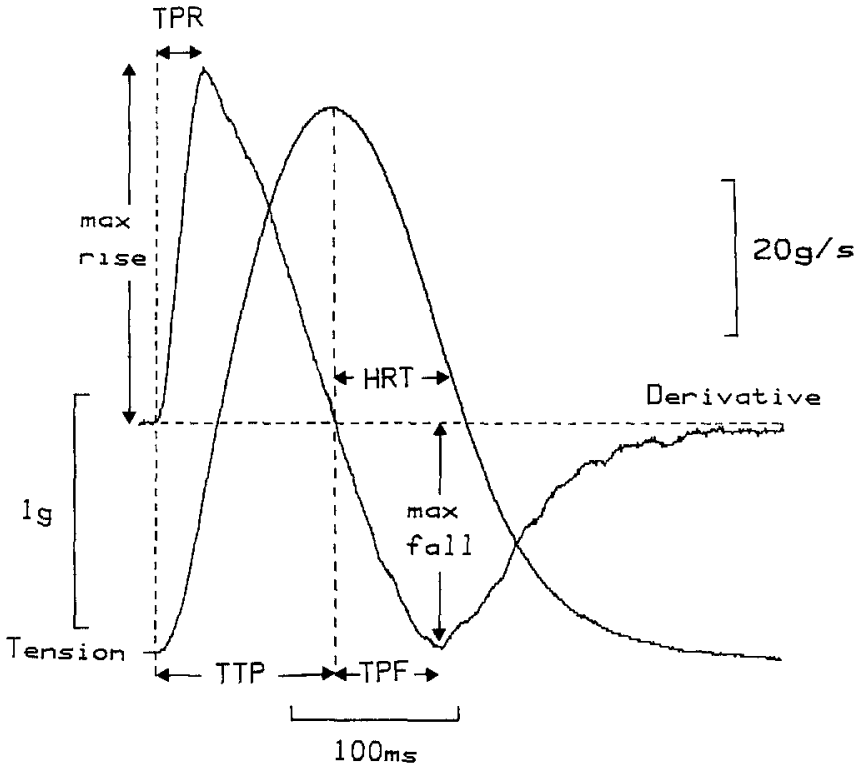

Fig. 1. A typical recording of a cardiac muscle twitch and its differentiated derivative to illustrate the contractile measurements. For the tension trace, developed tension (DT) in g, time to peak tension (TTP), and half relaxation time (HRT) in ms were measured. For the derivative, time to reach peak rate of tension rise (TPR), and fall (TPF) in ms as well as maximum rise and fall rates in $\mathrm{g} / \mathrm{s}$ were measured

(Grass Instruments type FT-03, Quincy, Mass, USA) by a fine gold chain. The transducer was mounted on a micromanipulator which was adjusted to place the muscle under an initial resting tension of $0.5 \mathrm{~g}$. The bath was filled with Krebs-Ringer solution $\left(144.0 \mathrm{Na}^{+}\right.$, $5.0 \mathrm{~K}^{+}, 2.5 \mathrm{Ca}^{2+}, 1.1 \mathrm{Mg}^{2+}, 25.0 \mathrm{HCO}_{3}{ }^{-}, 1.1 \mathrm{PO}_{4}{ }^{2-}, 1.1 \mathrm{SO}_{4}{ }^{2-}$, 11.0 glucose, in mmol/l) gassed with $95 \% \mathrm{O}_{2} 5 \% \mathrm{CO}_{2}$ (pH 7.35) and maintained over a range of $30 \pm 0.2^{\circ} \mathrm{C}$. Muscles were stimulated supramaximally at a rate of $0.1 \mathrm{~Hz}$ with $5-10 \mathrm{~ms}$ pulses from a constant current stimulator $(60-200 \mathrm{~mA})$ via platinum plate electrodes. The tension transducer output was amplified and high frequencies were filtered out ( $50 \mathrm{~Hz}$ cutoff). The signal was also differentiated using a high-pass circuit (low frequency cutoff $1.6 \mathrm{~Hz}$ ) with a high frequency attenuation above $800 \mathrm{~Hz}$, which gave an output linearly related to the rate of tension change. Active tension produced by the muscles increased over the initial $0.5-1 \mathrm{~h}$ and then stabilised. Muscle length was then carefully increased until optimal for maximum tension production. Measurements of isometric twitch parameters were made on five twitches for each muscle.

Figure 1 shows typical twitch and differentiated tension traces for a papillary muscle to illustrate measurements. Resting tension, developed tension, time to peak twitch tension (TTP), time to reach the peak rate of tension rise, maximum rise rate, half relaxation time (HRT), time to reach the maximum rate of tension fall during relaxation and the maximum fall rate were measured. Muscle length and weight were used to estimate cross-sectional area. Tensions were then expressed per cross-sectional area in order to correct for differences in muscle size. Rate results (measured in $\mathrm{g} / \mathrm{s}$ ) were expressed per tension (units of $s^{-1}$ ) to take into account the differences in tension production between muscles. Results were rejected if muscles failed to produce tensions greater than $1 \mathrm{~g} / \mathrm{mm}^{2}$. This a priori criterion, is similar to that applied by others [4].

Following measurement of 'resting' contractile properties, the effect of stimulation frequency was investigated. Muscles were stimulated at rates between 0.1 and $4.0 \mathrm{~Hz}$ for 2 min periods. The last contraction was used to measure twitch parameters. Muscles were allowed to recover to resting $(0.1 \mathrm{~Hz})$ tension between stimulations.

The final part of the investigation concerned the effects of temperature. Bath temperature was reduced to $25^{\circ} \mathrm{C}$ from $30^{\circ} \mathrm{C}$ gradually over a $15 \mathrm{~min}$ period and papillary muscles were allowed to equilibrate for a further $15 \mathrm{~min}$ before contractile properties were measured at a stimulation rate of $0.067 \mathrm{~Hz}$. The temperature was then returned to $30^{\circ} \mathrm{C}$ and equilibrated. The temperature was raised further to $37^{\circ} \mathrm{C}$ and measurements were made using a stimulation rate of $0.1 \mathrm{~Hz}$. The temperature was finally lowered to $30^{\circ} \mathrm{C}$ to check for recovery.

Ventricular muscle polyol levels were estimated from samples taken immediately after dissection and frozen in liquid $\mathrm{N}_{2}$. Trimethylsilyl derivatives were prepared from aqueous deproteinised extracts and analysed by gas chromatography [10].

\section{Statistical analysis}

Results are expressed as mean \pm SEM. Data were subjected to one way ANOVA, and any statistically significant differences were assigned to groups at the $5 \%$ or $1 \%$ levels using a modified form of the Duncan multiple range test $[11,12]$. Linear regression analysis was performed on some of the data from individual rats and mean group slopes and intercepts were compared as above.

\section{Results}

Data for the general condition of the animals, ventricle weights and polyol levels are given in Table 1. Irrespective of treatment, diabetic animals showed a 7-fold increase in plasma glucose, accompanied by persistent polyuria and hyperphagia. All diabetic control rats developed visible cataracts by the time of the final experiments, but none were noted in the ARI treated group. Body weight losses were similar in both diabetic groups. Ventricular weight was not significantly affected by diabetes, the relative muscle sparing being evident by a $26 \%$ increase in ventricle/body weight ratios in treated and untreated diabetic animals compared to normal controls.

Table 1. Body and ventricle weights, plasma glucose and ventricular polyols

\begin{tabular}{|c|c|c|c|c|c|c|}
\hline Group & (g) & Ventricle weight & $\begin{array}{l}\text { Ventricle/body } \\
\text { weight ratio } \\
\left(\mathrm{x} 10^{3}\right)\end{array}$ & $\begin{array}{l}\text { Plasma glucose } \\
(\mathrm{mmol} / \mathrm{l})\end{array}$ & $\begin{array}{l}\text { Ventricle sorbitol } \\
\text { (nmol/mg wet } \\
\text { weight) }\end{array}$ & $\begin{array}{l}\text { Ventricle } \\
\text { myo-inositol } \\
\text { (nmol/mg wet } \\
\text { weight) }\end{array}$ \\
\hline $\begin{array}{l}\text { Diabetic control } \\
(n=11)\end{array}$ & $386^{b} \pm 18$ & $0.921 \pm 0.030$ & $2.47^{b} \pm 0.10$ & $38.7^{b} \pm 4.3$ & $1.070^{\mathrm{b}} \pm 0.290$ & $0.70 \pm 0.05$ \\
\hline
\end{tabular}

Significant difference from normal control group; ${ }^{\mathrm{a}} p<0.05 ;{ }^{\mathrm{b}} p<0.01$; effect of aldose reductase inhibitor (ARI) treatment compared to diabetic controls; ${ }^{\mathrm{c}} p<0.01$; Results expressed as mean \pm SEM 

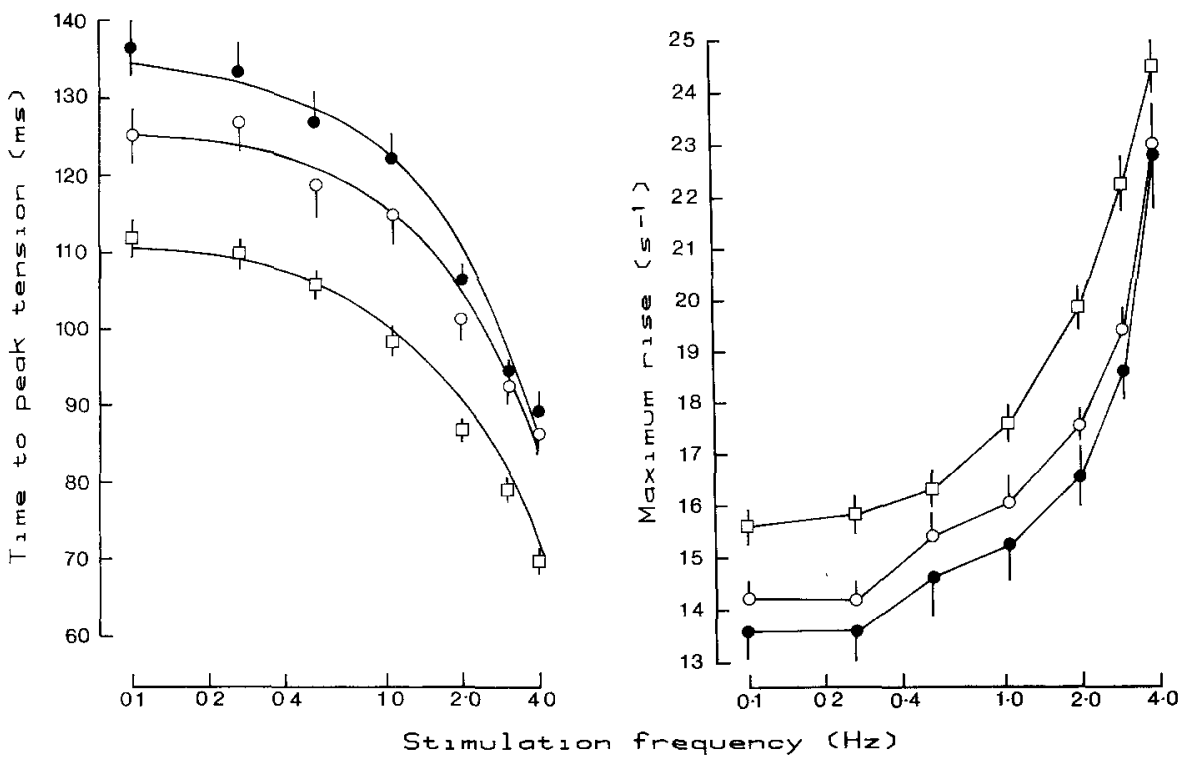

Fig. 2. Effect of stimulation frequency on contraction. $\square$ Normal controls $(n=21)$; - diabetic controls $(n=11) ; \bigcirc$ ARI treated diabetic rats $(n=12)$. Error bars show \pm SEM. Time to reach peak tension (left). Statistics: diabetic vs normal, $p<0.010 .1-4.0 \mathrm{~Hz}$; aldose reductase inhibitor (ARI) treated vs normal $p<0.01$ $0.1-4.0 \mathrm{~Hz}$; ARI treated vs diabetic $p<0.050 .1 \mathrm{~Hz}, \mathrm{NS} 0.27-4.0 \mathrm{~Hz}$. Regression curves: TTP $(\mathrm{ms})=$ slope $\mathrm{x}$ frequency $(\mathrm{Hz})+$ intercept. Slopes; $-10.98,-12.60$, $-10.68 \mathrm{~ms} / \mathrm{Hz}$; intercepts; $111.6,135.1$, $126.0 \mathrm{~ms}$ for normal, diabetic and ARI treatment groups, respectively. Maximum tension rise rate (right). Statistics: diabetic vs normal, $p<0.050 .53 \mathrm{~Hz}, p<0.010 .1$, $0.27,1.07,2.0,3.0 \mathrm{~Hz}$, NS $4.0 \mathrm{~Hz}$; ARI treated vs normal, $p<0.050 .27,1.07 \mathrm{~Hz}$, $p<0.01,0.1,2.0,3.0 \mathrm{~Hz}, \mathrm{NS} 0.53,4.0 \mathrm{~Hz}$; ARI treated vs diabetic, NS $0.1-4.0 \mathrm{~Hz}$. NS: no significant difference
Ventricle sorbitol levels were low in normal rats and increased 17 -fold with diabetes. Sorbitol was reduced by $67 \%$ with ARI treatment but levels remained significantly above normal $(p<0.05)$. Free myo-inositol concentration was unaffected by diabetes or ARI treatment.

\section{Contractile properties}

Results of the contractile measurements at a "resting" stimulation rate of $0.1 \mathrm{~Hz}$ are given in Table 2. There were no significant differences in passive or developed tension between the groups. Contraction times were increased in the diabetic animals. Time to peak tension (TTP) was slowed by $21 \%$ in diabetic controls, but was slowed to a lesser extent $(11 \%)$ in the ARI treated group. Whilst the time taken to reach maximum rate of tension rise was unaffected, diabetes decreased the maximum rise rate by $13 \%$ and $9 \%$ for the control and ARI treated groups, respectively.

Relaxation was more severely affected than contraction. Half relaxation times (HRT) were $29 \%$ slower than normal in the diabetic control group. With ARI treatment, HRT was only $4 \%$ slowed. The time taken to reach peak rate of tension fall was delayed in diabetic controls by $36 \%$, and the maximum fall rate was reduced by $19 \%$.
With ARI treatment, maximum fall rate was normal, and the time taken to reach it was only slightly $(10 \%)$ delayed.

\section{Effects of stimulation frequency}

Developed tension decreased with increasing stimulus frequency in all muscles, reaching $37.3 \pm 2.8,36.9 \pm 5.0$ and $39.8 \pm 4.4 \%$ of resting values at $4 \mathrm{~Hz}$ for normal, diabetic and ARI treated groups, respectively. There was no significant difference between groups.

The effect of stimulus frequency on TTP is shown in Figure 2. TTP declined with frequency by a similar amount in all groups, reaching 47,48 , and $46 \%$ of resting values at $4 \mathrm{~Hz}$ for normal, diabetic and ARI treated animals, respectively. Linear regression of TTP against frequency showed that there were no significant differences in slope for the 3 groups. However, intercepts were different, being elevated by $21 \%$ and $13 \%$ for diabetic and ARI treated groups compared to the normal control group ( $p<0.01$ for both comparisons). Although differences between diabetic and ARI treated animals suggested a $39 \%$ prevention of TTP slowing, this did not reach statistical significance.

Figure 2 also shows the increase in maximum rise rate with increasing frequency. Regression analysis re-

Table 2. Papillary muscle contractile properties

\begin{tabular}{|c|c|c|c|c|c|c|c|c|}
\hline Group & $\begin{array}{l}\text { DT } \\
\left(\mathrm{g} / \mathrm{mm}^{2}\right)\end{array}$ & $\begin{array}{l}\text { RT } \\
\left(\mathrm{g} / \mathrm{mm}^{2}\right)\end{array}$ & $\begin{array}{l}\text { TTP } \\
(\mathrm{ms})\end{array}$ & $\begin{array}{l}\text { TPR } \\
(\mathrm{ms})\end{array}$ & $\begin{array}{l}\text { Maximum } \\
\text { rise rate } \\
\left(\mathrm{s}^{-1}\right)\end{array}$ & $\begin{array}{l}\text { HRT } \\
\text { (ms) }\end{array}$ & $\begin{array}{l}\mathrm{TPF} \\
(\mathrm{ms})\end{array}$ & $\begin{array}{l}\text { Maximum } \\
\text { fall rate } \\
\left(\mathrm{s}^{-1}\right)\end{array}$ \\
\hline $\begin{array}{l}\text { Normal control } \\
(n=21)\end{array}$ & $3.2 \pm 0.4$ & $2.2 \pm 0.3$ & 112.4 & $30.6 \pm 0.6$ & $15.5 \pm 0.3$ & \pm 2.5 & \pm 2.2 & $8.9 \pm 0.3$ \\
\hline $\begin{array}{l}\text { Diabetic control } \\
(n=11)\end{array}$ & $3.4 \pm 0.6$ & $2.4 \pm 0.3$ & $136.3^{\mathrm{a}} \pm 3.6$ & $32.1 \pm 1.5$ & $13.6^{\mathrm{a}} \pm 0.5$ & $116.2^{\mathrm{a}} \pm 4.2$ & $102.6^{\mathrm{a}} \pm 4.3$ & $7.2^{\mathrm{a}} \pm 0.2$ \\
\hline $\begin{array}{l}\text { ARI treated } \\
(n=12)\end{array}$ & $2.7 \pm 0.5$ & $2.6 \pm 0.3$ & $125.4^{\mathrm{a}, \mathrm{b}} \pm 4.0$ & $31.2 \pm 0.8$ & $14.2^{\mathrm{a}} \pm 0.3$ & $94.2^{c} \pm 3.2$ & $83.5^{\mathrm{c}} \pm 3.4$ & $8.6^{\mathrm{C}} \pm 0.3$ \\
\hline
\end{tabular}

Results expressed as mean \pm SEM. Significant difference from normal control group; ${ }^{\mathrm{a}} p<0.01$; effect of ARI treatment compared to diabetic controls; ${ }^{\mathrm{b}} p<0.05,{ }^{\mathrm{c}} p<0.01$; DT, developed tension; RT, resting tension; TTP, time to peak tension; TPR, time to peak rate of tension rise; HRT, half relaxation time; TPF, time to peak rate of tension fall 

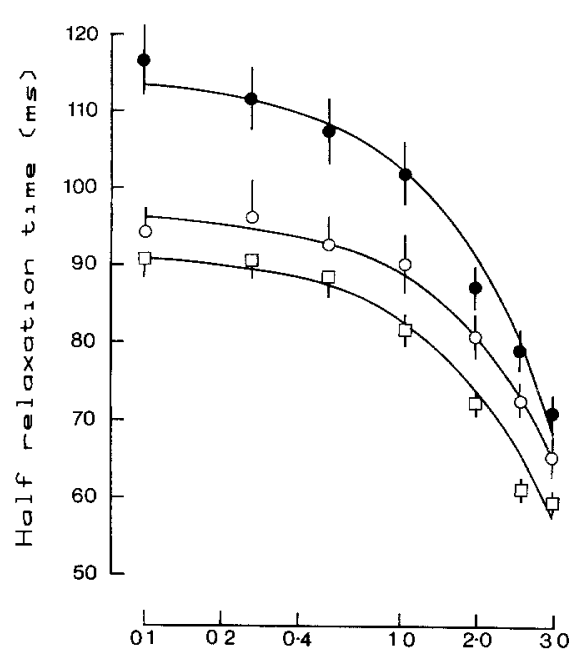

Stimulation frequenay $(\mathrm{Hz})$

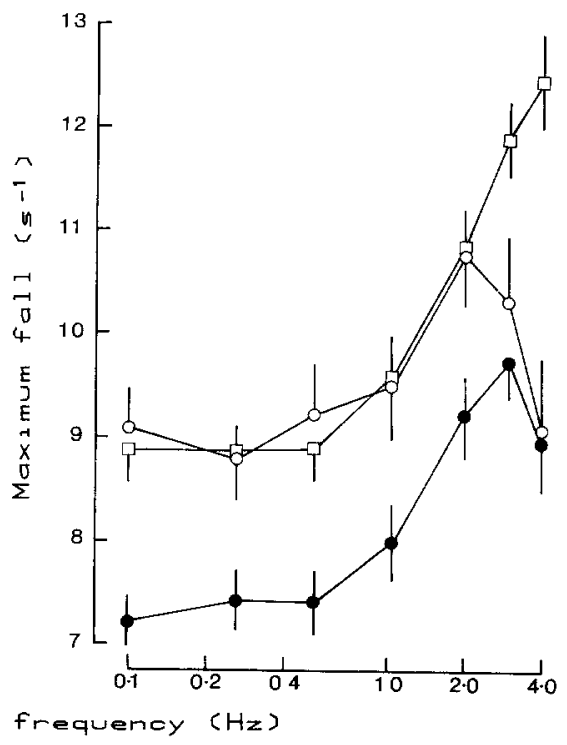

Fig.3. Effects of stimulation frequency on relaxation. $\square$ Normal controls $(n=21)$; diabetic controls $(n=11)$; O ARI treated diabetic rats $(n=12)$. Error bars show \pm SEM. Half relaxation time (left). Statistics: diabetic vs normal, $p<0.010 .1-4.0 \mathrm{~Hz}$; ARI treated vs normal $p<0.052 .0,4.0 \mathrm{~Hz}, p<0.013 .0 \mathrm{~Hz}$, NS $0.1-1.07 \mathrm{~Hz}$; ARI treated vs diabetic, $p<0.05$ $1.07 \mathrm{~Hz}, p<0.010 .1-1.07 \mathrm{~Hz}$, NS $2.0-4.0 \mathrm{~Hz}$. Regression curves: $\mathrm{HRT}(\mathrm{ms})=$ slope $\mathrm{x}$ frequency $(\mathrm{Hz})+$ intercept. Slopes; $-8.94,-11.64$, $-7.98 \mathrm{~ms} / \mathrm{Hz}$; intercepts $91.6,114.4,96.9 \mathrm{~ms}$ for normal, diabetic and ARI treatment groups, respectively. Maximum relaxation rate (right). Statistics: diabetic vs normal, $p<0.051 .07,2.0 \mathrm{~Hz}$, $p<0.010 .1-0.53,3.0,4.0 \mathrm{~Hz}$; ARI treated vs normal, $p<0.053 .0 \mathrm{~Hz}, p<0.014 .0 \mathrm{~Hz}$, NS $0.1-2.0 \mathrm{~Hz}$; ARI treated vs diabetic, $p<0.05$ $0.27,1.07,2.0 \mathrm{~Hz}, p<0.010 .1,0.53 \mathrm{~Hz}$, NS 3.0 , $4.0 \mathrm{~Hz}$.

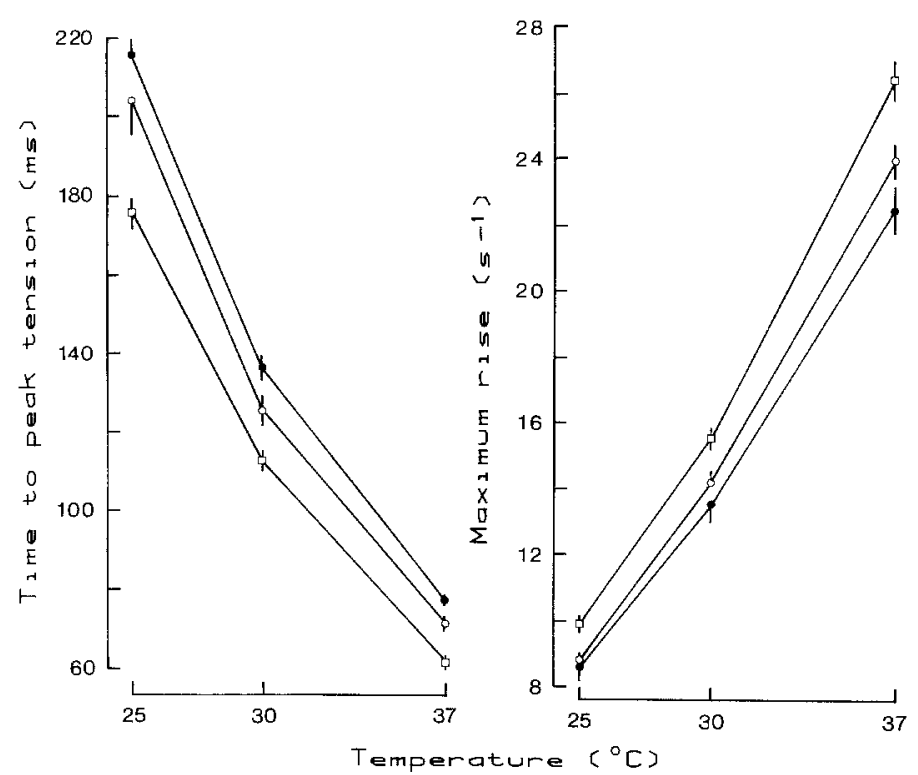

Fig.4. Effect of temperature on contraction. $\square$ Normal controls $(n=21)$; diabetic controls $(n=11) ; O$ ARI treated diabetic rats $(n=12)$. Error bars show \pm SEM. Time to peak tension (left). Statistics: normal vs diabetic or ARI treated, $p<0.01$ at all temperatures; diabetic vs ARI treated, NS at 25 and $p<0.05$ at 30 and $37^{\circ} \mathrm{C}$. Maximum rate of tension rise (right). Statistics: normal vs diabetic, $p<0.01$ at all temperatures; normal vs ARI treated, $p<0.05$ at 25 and $p<0.01$ at 30 and $37^{\circ} \mathrm{C}$; diabetic vs ARI treated, NS at all temperatures

vealed no significant differences between the slopes of the curves for different groups. Compared with normal muscles, intercepts were reduced by $14 \%$ for diabetic $(p<0.01)$ and $9 \%$ for ARI treated groups $(p<0.01)$. There was no significant effect of ARI treatment.

Data pertaining to relaxation are shown in Figure 3. HRT decreased with frequency. Below $2 \mathrm{~Hz}$ ARI treated values were lower than those for the diabetic group, and were similar to normal controls. Between 2 and $4 \mathrm{~Hz}$ some differences between ARI treated and normal values were revealed. Regression analysis showed that there were no significant differences between slopes or intercepts for normal and ARI treated animals, and both variables were greater in diabetic animals $(p<0.01)$.

Also plotted in Figure 3 are maximum rates of relaxation which increased with stimulation frequency in normal muscles. In diabetic animals relaxation was depressed and although it increased in the mid frequency range, it was also depressed at $4 \mathrm{~Hz}$. In the ARI treated group, maximum relaxation rate followed the normal pattern closely up to $2 \mathrm{~Hz}$. Thereafter the rate declined to that similar to diabetic muscle values at $4 \mathrm{~Hz}$.

\section{Effects of temperature}

There was no significant change in developed tension between 25 and $30^{\circ} \mathrm{C}$ for any group. However, at $37^{\circ} \mathrm{C}$ tension fell in the normal group by $24.6 \pm 2.1 \%$. The fall was significantly less in diabetic $(6.9 \pm 2.4 \% ; p<0.01)$ and ARI treated $(3.8 \pm 2.3 \% ; p<0.01)$ animals.

Figure 4 shows the effects of temperature on contraction times. TTP decreased with increasing temperature in all groups, and it was slower in diabetic control animals than in normal animals. There were no significant effects of ARI treatment at $25^{\circ} \mathrm{C}$ but TTP was partially normalised at 30 and $37^{\circ} \mathrm{C}$. The maximum rate of tension rise was increased with an increase in temperature, and diabetic animals had reduced rates compared to normal animals. There were no significant effects of ARI treatment.

Effects on relaxation are illustrated in Figure 5. HRT was reduced with increasing temperature in all groups, and remained slowed in diabetic controls compared to normal animals. There were no differences in HRT between ARI treated and normal animals at 25 and $30^{\circ} \mathrm{C}$. However, HRT was slower in the ARI group at $37^{\circ} \mathrm{C}$. A similar pattern was seen for maximum relaxation rate. The difference between diabetic and normal animals increased from $17 \%$ at $25^{\circ} \mathrm{C}$ to $30 \%$ at $37^{\circ} \mathrm{C}$. ARI treatment resulted in normal relaxation rates at 25 and $30^{\circ} \mathrm{C}$ but at $37^{\circ} \mathrm{C}$, the rate was $15 \%$ less than for normal animals. 


\section{Discussion}

The data demonstrate that diabetes slows contraction and relaxation of cardiac muscle, which is in general agreement with the conclusions of Fein and co-workers [4] for isotonic and isometric responses from streptozotocin treated rats. It is unlikely that the contractile deficits resulted from a general cytotoxic effect of streptozotocin as they were reversed by insulin treatment in another study using streptozotocin-diabetic rats [6]. Similar changes were also found in alloxan treated rabbits and were also prevented by insulin treatment [5]. Thus, the effects seem not to depend on species or diabetogenic agent. The clear beneficial actions of ARI treatment on papillary muscle mechanics, which have not been reported previously, strongly suggest polyol pathway involvement in diabetic cardiomyopathy in rats.

TTP measurements at low stimulation frequencies and higher temperatures showed that ARI treatment was able to partially correct the deficit caused by diabetes. There was, however, less effect on maximum rates of tension production. Excitation-contraction coupling depends on several processes. Extracellular $\mathrm{Ca}^{2+}$ moves into cells through sarcolemma ion channels, acting as a secondary source for activation of the contractile machinery and inducing the release of sarcoplasmic reticulum $\mathrm{Ca}^{2+}$. The inositol transduction mechanism [13] is potentially important, as the action potential may cause inositol triphosphate mediated sarcoplasmic reticulum $\mathrm{Ca}^{2+}$ release. There is also a potential contribution from $\mathrm{Na}^{+} / \mathrm{Ca}^{2+}$ exchange mechanisms in the sarcolemma. In the mammalian heart it is likely that the bulk of $\mathrm{Ca}^{2+}$ for activation cycles between the sarcoplasmic reticulum and contractile proteins on a beat by beat basis, with sarcolemmal mechanisms operating to maintain the longer term $\mathrm{Ca}^{2+}$ economy of the heart [14]. In addition, the maximum rate of tension development depends on ATP availability and its hydrolysis rate by actomyosin [15]. Part of the observed contraction slowing may be caused by changes in myosin isoenzyme content as a shift towards slower isomyosins has been demonstrated in the diabetic rat ventricle [16]. Fast to slow myosin transformations have also been shown functionally and histochemically in diabetic soleus skeletal muscle. These transformations were prevented by insulin but were unaffected by ARI administration [8]. The change to slow isomyosins could, therefore, explain the similar decline in maximum rates of tension development observed in diabetic control and ARI treated groups. The measure of TTP should be influenced by all of the processes involved in excitation-contraction coupling. Thus, while ARI treatment may not affect isomyosin composition, it could, nevertheless, effect the inositol transduction mechanism or sarcoplasmic reticulum $\mathrm{Ca}^{2+}$ handling, which could be reflected in TTP measurements. As there was no change in vetricular free myo-inositol concentration in the present experiments, the $\mathrm{Ca}^{2+}$ handling hypothesis may provide a more likely explanation of the TTP changes than effects on inositol transduction.

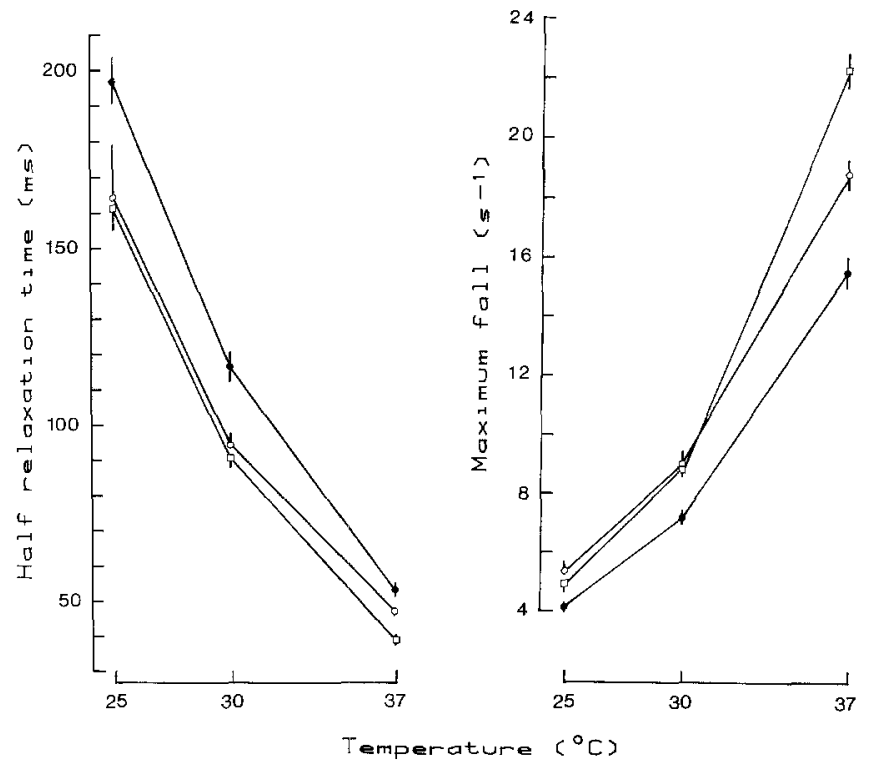

Fig.5. Effect of temperature on relaxation. $\square$ Normal controls $(n=21)$; diabetic controls $(n=11)$; O ARI treated diabetic rats $(n=12)$. Error bars show \pm SEM. Half relaxation time (left). Statistics: normal vs diabetic, $p<0.01$ at all temperatures; normal vs ARI treated, NS at 25 and 30 and $p<0.01$ at $37^{\circ} \mathrm{C}$; diabetic vs ARI treated, $p<0.01$ at all temperatures. Maximum rate of tension fall (right). Statistics: normal vs diabetic, NS at 25 and $p<0.01$ at 30 and $37^{\circ} \mathrm{C}$; normal vs ARI treated, NS at 25 and 30 and $p<0.01$ at $37^{\circ} \mathrm{C}$; diabetic vs ARI treated, $p<0.05$ at 25 and $p<0.01$ at 30 and $37^{\circ} \mathrm{C}$

A major defect in diabetic papillary muscle performance, largely prevented by ARI treatment, was the slowing of relaxation. This was noted for all measurements; HRT, maximum fall rate, and time to reach maximum relaxation, at all but the highest stimulation frequencies. The slowing probably also relates to defective $\mathrm{Ca}^{2+}$ handling. In the isolated whole heart preparation cardiac output in diabetic animals was more affected than normal by decreased extracellular calcium [17]. $\mathrm{Ca}^{2+}$-ATPase activity is reduced in streptozotocindiabetic rat ventricular sarcoplasmic reticulum [18] and sarcolemma [19], and this is reversed by insulin treatment [20]. It would appear, therefore, that ARI treatment may normalise $\mathrm{Ca}^{2+}$-ATPase activity, although this requires direct confirmation. Possible morphological correlates of a $\mathrm{Ca}^{2+}$ related deficit are the findings of t-tubule and sarcoplasmic reticulum swelling [21] and intracellular oedema around the sarcoplasmic reticulum [22]. In view of the present contractile effects of ARI treatment, it is ternpting to speculate that polyol accumulation and the resulting osmotic effects could be responsible for this oedema, as has been postulated for disruptions to lens structure. However, the level of sorbitol found in diabetic controls, although greater than normal, is probably too low to be considered a serious source of osmotic insult.

At the highest stimulation frequencies, relaxation in diabetic and ARI treated groups was similar, particularly for maximum rates, where the relaxation rate at $4 \mathrm{~Hz}$ was reduced when compared to both lower frequencies of stimulation and to normal controls. This may repre- 
sent a separate diabetic effect, not corrected by ARI treatment. It could be caused by interference between successive muscle action potentials as repolarisation of ventricular cells is slowed by diabetes [23].

Raising the bath temperature to $37^{\circ} \mathrm{C}$ produced a greater tension drop in the normal than the diabetic rat muscles. Normally the magnitude of this drop depends on the size of a muscle and is probably due to hypoxia in its core [24]. As there was little difference in size between the groups, the present results suggest that diabetic muscles are less sensitive to hypoxia. This may appear paradoxical as the diabetic myocardium is more sensitive than normal to ischaemia [25] when the vasculature is perfused. However, mitochondria are swollen and have disrupted christae, and abnormal fat and glycogen deposits are seen in diabetic rat ventricle [21], suggesting that the normal oxidative metabolism may be compromised. In vitro, when not restricted by the vascular supply, cardiac muscle from diabetic rats may, therefore, have reduced oxygen demands and exhibit resistance to hypoxia.

Extrapolation from in vitro contractile measurements to in vivo haemodynamic properties of the whole heart must be approached with extreme caution, particularly if applied to different species. However, the slowing of contraction and relaxation could potentially explain effects in diabetic patients, such as reduced left ventricular ejection time and prolongation of the isovolumetric relaxation phase. It could also account for similar changes observed in animal models [1-3]. The data clearly demonstrate beneficial effects of ARI treatment on cardiomyopathy in diabetic rats, which may be interpreted in terms of preventing $\mathrm{Ca}^{2+}$ handling deficits. Whether this also applies to patients is unknown but it would seem to be an area worthy of study.

Acknowledgements. This work was supported by a grant from the British Heart Foundation. We are grateful to Dr Don Mirrlees of Imperial Chemical Industries plc for supplying the ARI ponalrestat, and for help with polyol analyses, to Dr Don Stribling for encouragement, and to Dr Valerie Flook for advice on statistical analysis.

\section{References}

1. Fein FS, Sonnenblick EH (1985) Diabetic cardiomyopathy. Prog Cardiovase Dis 27: 255-270

2. Regan TJ, Ettinger PO, Kahn MI, Jesrani MU, Lyons M, Oldewurtel HA, Weber M (1974) Altered myocardial function and metabolism in chronic diabetes mellitus without ischemia in dogs. Circ Res 35: 222-237

3. Penpargkul S, Schaible T, Yiptinsoi T, Scheuer J (1980) The effects of diabetes on performance and metabolism of rat hearts. Circ Res 47: 911-921

4. Fein FS, Kornstein LB, Strobeck JE, Capasso JM, Sonnenblick EH (1980) Altered myocardial mechanics in diabetic rats. Circ Res 47: $922-933$

5. Fein FS, Miller-Green B, Sonnenblick EH (1985) Altered myocardial mechanics in diabetic rabbits. Am $J$ Physiol 248: H729-H736

6. Fein FS, Strobeck JE, Malhotra A, Scheuer J, Sonnenblick EH (1981) Reversibility of diabetic cardiomyopathy with insulin in rats. Circ Res 49: 1251-1261
7. Cameron NE, Cotter M, Robertson S (1987) Effects of experimental diabetes on contractile properties of skeletal muscles of the rat and the effect of treatment with the aldose reductase inhibitor Statil (ICI 128436). J Physiol 387: 43P (Abstract)

8. Cameron NE, Cotter M, Robertson S (1987) Effects of insulin and aldose reductase inhibitor treatment on contractile properties of rat skeletal muscles with long-term experimental diabetes. J Physiol 391: 83P (Abstract)

9. Stribling D, Mirrlees DJ, Harrison HE, Earl DCN (1985) Properties of ICI 128,436 , a novel aldose reductase inhibitor and its effects on diabetic complications in the rat. Metabolism 34: 336-344

10. Cameron NE, Leonard MB, Ross IS, Whiting PH (1986) The effects of Sorbinil on peripheral nerve conduction velocity, polyol concentrations and morphology in the streptozotocin-diabetic rat. Diabetologia 29: 168-174

11. Duncan DB (1955) Multiple range and multiple F tests. Biometrics 11: $1-42$

12. Kramer CY (1956) Extension of multiple range tests to group means with unequal numbers of replications. Biometrics 12: $307-310$

13. Abdel-Latif AA (1986) Calcium-mobilising receptors, polyphosphoinositides, and the generation of second messengers. Pharmacol Rev 38: 227-272

14. Chapman RA (1983) Control of cardiac contractility at the cellular level. Am J Physiol 245: H535-H552

15. Barany M (1967) ATPase activity of myosin correlated with speed of shortening. J Gen Physiol 50 (Suppl 2): 197-218

16. Pierce GN, Dhalla NS (1981) Cardiac myofibrillar ATPase activity in diabetic rats. J Mol Cell Cardiol 13: 1063-1069

17. Bielefeld DR, Pace CS, Boshell BR (1983) Altered sensitivity of chronic diabetic rat heart to calcium. Am J Physiol 245: E560-E567

18. Penpargkul S, Fein F, Sonnenblick EH, Scheuer J (1981) Depressed cardiac sarcoplasmic reticular function from diabetic rats. J Mol Cell Cardiol 13: 303-309

19. Heygler CE, Prakash A, McNeill JH (1987) Alterations in cardiac sarcolemmal $\mathrm{Ca}^{2+}$ pump activity during diabetes mellitus. Am J Physiol 252: H540-H544

20. Ganguly PK, Pierce GN, Dhalla KS, Dhalla NS (1983) Defective sarcoplasmic reticular calcium transport in diabetic cardiomyopathy. Am J Physiol 244: E528-E535

21. Hsiao Y-C, Suzuki K, Abe H, Totota T (1987) Ultrastructural alterations in cardiac muscle of diabetic BB wistar rats. Virchows Arch [A] 411: 45-52

22. McGrath GM, McNeill JH (1986) Cardiac ultrastructural changes in streptozotocin-induced diabetic rats: effects of insulin treatment. Can J Cardiol 2: 164-269

23. Sauviat MP, Feuvray D (1986) Electrophysiological analysis of the sensitivity to calcium in ventricular muscle from alloxan diabetic rats. Basic Res Cardiol 81: 489-496

24. Frezza WA, Bing OHL (1976) $\mathrm{Po}_{2}$-modulated performance of cardiac muscle. Am J Physiol 231: 1620-1624

25. Hearse DJ, Stewart DA, Chain EB (1975) Diabetes and the survival and recovery of the anoxic myocardium. J Mol Cell Cardiol 7: 397-415

Received: 8 December 1988

and in revised form: 28 March 1989

Dr. N.Cameron

Department of Physiology

Marischal College

University of Aberdeen

Aberdeen AB9 1AS

Scotland

UK 